\title{
Primer kemik kayıplarında total diz protezi uygulaması
}

\author{
Total knee prosthesis application in primary bone loss
}

\author{
Demet Pepele Kurdal ${ }^{1}$, Volkan Ezici², Nurzat Elmalı² \\ ${ }^{1}$ SBÜ, Fatih Sultan Mehmet Eğitim ve Araştırma Hastanesi, Ortopedi ve Travmatoloji Kliniği, İstanbul \\ ${ }^{2}$ Bezmialem Vakıf Üniversitesi Tıp Fakültesi, Ortopedi ve Travmatoloji Ana Bilim Dalı, İstanbul
}

\begin{abstract}
Primer total diz protezinde kemik kaybı revizyon total diz protezine göre nadirdir. Primer protezde karşılaşılan kemik kaybı genellikle küçüktür ve çoğunlukla tibial yüzeydedir. Varus ve fleksiyon deformitesi sık olduğu için kemik kaybı en sık tibianın posteromedial köşesindedir. Kemik kaybı, ameliyat sırasında implantların uygun dizilimini ve stabil bir implant-kemik ara yüzeyini sağlamada sorun oluşturabilir. Kemik kaybının tedavisini planlarken defektin etiyolojisini, sınıflamasını, kullanılacak protezleri, tüm tedavi seçeneklerini ve cerrahi teknikleri anlamak gereklidir. Tedavideki amaç; kemik stoğunu korumaya, implantı güçlü yapısal kemiğe sabitlemeye, anatomik bir eklem hattını yeniden oluşturmaya, fleksiyon-ekstansiyon stabilitesini yeniden sağlamaya odaklanmalıdır.
\end{abstract}

Anahtar sözcükler: gonartroz; artroplasti; kemik greft; metal destek
Bone loss in primary total knee arthroplasty is rare compared to revision total knee arthroplasty. Bone loss encountered in primary arthroplasty is usually minor and mostly at the tibial surface. Since varus and flexion deformities are common, bone loss is most common in the posteromedial corner of the tibia. Bone loss may pose a problem in maintaining proper alignment of implants and a stable implantbone interface during surgery. When planning the treatment of bone loss, it is necessary to understand the etiology of the defect, its classification, the prosthesis to be used, all treatment options and surgical techniques. The aim of treatment; It should focus on preserving bone stock, anchoring the implant to strong structural bone, recreating an anatomical joint line, restoring flexion-extension stability.

Key words: gonarthrosis; arthroplasty; bone graft; metal augment

Dizin varus veya valgus deformitesinde, medial veya lateral kompartmanın aşırı yüklenmesine bağlı subkondral kemiğin kollapsı ile kemik kaybı ortaya çıkar. ${ }^{[2]}$ Tipik olarak varus dizde kemik kaybı öncelikle posteromedial periferik kısımda olmak üzere medial tibial platoda çökmeye neden olurken valgus dizde kemik kaybı hem tibiada kaviter santral defekt olarak hem de femurda distal ve posterior yüzeyde çökme olarak görülür (Tablo 1) ${ }^{[1]}$ (Şekil 1).

\section{SINIFLAMA}

Hem primer hem de revizyon diz protezi ameliyatlarında karşılaşılan kemik kayıpları için çeşitli sınıflandırma sistemleri geliştirilmiştir. Bu sınıflandırmaların çoğu distal femur veya proksimal tibiada metafiziyel segmentteki kemik kaybının durumuna göre yapılır (kaviter veya segmenter, kortikal veya kansellöz, santral veya periferal). ${ }^{[3-7]}$

iletişim / Contact: Prof. Dr. Nurzat Elmalı • E-posta / E-mail: nelmali@bezmialem.edu.tr

ORCID iD: Demet Pepele Kurdal, 0000-0003-2669-3020 • Volkan Ezici, 0000-0001-6335-703X • Nurzat Elmalı, 0000-0001-8896-2973

Geliş / Received: 13 Temmuz 2021 • Kabul / Accepted: 26 Temmuz 2021 
Tablo 1. Primer total diz protezinde kemik kaybının başlıca nedenleri[1]

Osteonekroz
Tibial plato veya femoral kondillerin kırık sekeli
Kemik kistleri
Önceki tibial osteotomiler
Enflamatuvar artropatiler
Enfeksiyon

Tablo 2. Primer ve revizyon total diz protezinde kemik kaybının sınıflaması ${ }^{[6]}$

\begin{tabular}{lccc}
\hline Tip & \multicolumn{2}{c}{$\begin{array}{c}\text { Tek kondil veya } \\
\text { hemiplato tutulumu }\end{array}$} & $\begin{array}{c}\text { Derinlik } \\
(\mathrm{mm})\end{array}$ \\
\hline I $(\mathrm{a} / \mathrm{b})$ & Minimal & $<\% 50$ & $<5$ \\
II $(\mathrm{a} / \mathrm{b})$ & $>\% 50$ & $<\% 70$ & $5-10$ \\
III $(\mathrm{a} / \mathrm{b})$ & $>\% 70$ & $<\% 90$ & $>10$ \\
IV $(\mathrm{a} / \mathrm{b})$ & $>\% 90$ & & $>10$ \\
\hline
\end{tabular}

a, periferal kenar sağlam; b, periferal kenar defektif.

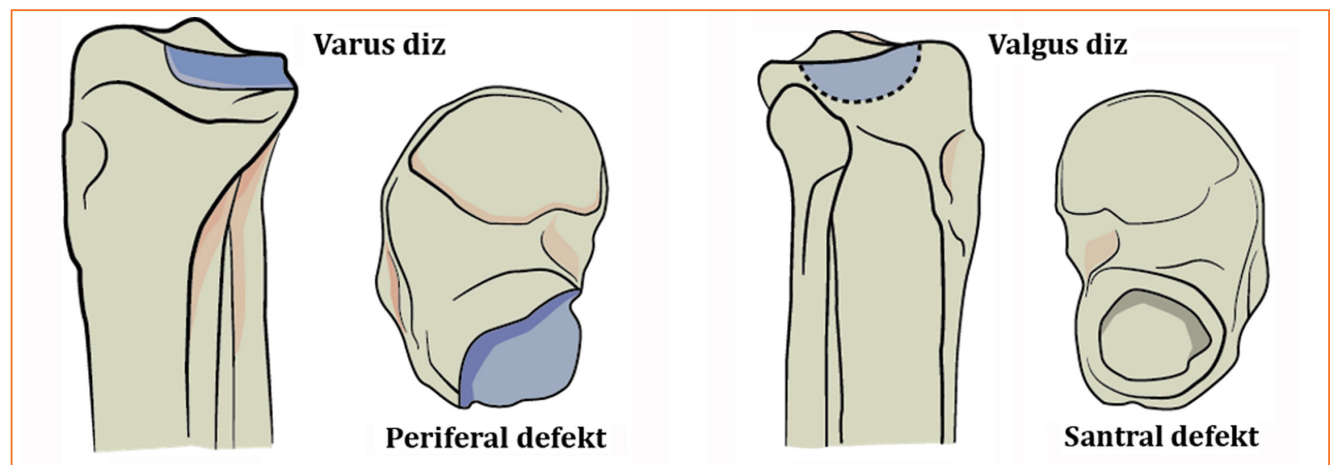

Şekil 1. Varus ve valgus dizde kemik kaybının yerleşimi.

Insall kemik defektlerini, contained (kaviter) ve uncontained (segmenter) olarak sınıflamıştır. Kaviter defekt sağlam kortikal kenara sahiptir, oysa segmenter defekte sağlam kortikal kenar yoktur. ${ }^{[4]}$

Bargar ve Gross, tibial kemik kayıplarını dört gruba ayırır ${ }^{[5]}$ :

Segmental: Eklem seviyesinde hem kortikal hem de kansellöz kemik yokluğu.

Kaviter: Kortikal kenarın sağlam olduğu eklem seviyesinde kansellöz kemik kaybı.

İnterkalar: Kemik kaybı, kemiğin merkezinde, genellikle eklem yüzeyinin altındadır ancak proksimal ve distalde kemik sağlamdır.

Devamsızlık (discontinuity): Kemik kırıkları veya kemiğin segmental bozukluğunun olmasıdır.

Rand, 1991 yılında kemik kayıplarını femoral kondil veya tibial plato içerisindeki defektin derinliğine ve kondil veya hemiplatonun etkilenen yüzdesine göre dört evrede sınıflandırmıştır. ${ }^{[6]}$ Minimal (tip I) defektler, 5 mm'den daha az derinlikte ve tek kondilin \%50'sinden daha azını etkileyen kemik kaybını; ılımlı (tip II) defektler, tek kondilin \%50-\%70'ini etkileyen 5-10 mm derinlikte kemik kaybını; ciddi (tip III) defektler, kondilin \%70'inden fazlasını etkiyen $10 \mathrm{~mm}$ veya daha geniş kemik kaybını tanımlar. Yaygın kaviter (tip IV) defektler ise sağlam periferal kenarı olanlar ve defektif periferal kenarı olanlar olarak ikiye ayrılır (Tablo 2). ${ }^{[6]}$

Kemik kaybı en sık varus dizin varlığında görülür ve sıklıkla tibianın posteromedial bölgesine lokalizedir. Lezyonun olduğu subkondral kemikte ciddi skleroz bulunur ve defekt genellikle 8-10 mm'yi aşmaz. Böyle hafif kemik kayıplarında tibial platonun rezeksiyonu yeterlidir ve ilave prosedür gerekmez. Buna karşılık 12 mm'den daha fazla kemik kaybının olduğu daha ciddi ve derin lezyonlarda dizdeki ligamentlerin de bütünlügü bozulur ve kalan kemiğin kalitesi azalır. Aşırı tibial rezeksiyon, eklem seviyesinin bozulmasına da neden olur. Bu durum kemik kaybının rekonstrüksiyonu için impaksiyon kemik greftleme veya yapısal allogreftler gibi ilave seçeneklerin uygulanmasını gerektirir.

Engh ve ark. tarafindan popularize edilen The Anderson Orthopaedic Research Institute (AORI) sınıflaması sıkıkla revizyon TDP için uygulanmaktadır. Defektler, beklenen kemik eksikliği için ameliyat öncesi radyografilere göre sınıflandırılır. Revizyon olgularında genellikle ameliyat sırasında ortaya çıkan kemik hasarı ameliyat öncesi değerlendirmeyle belirlenenden çok daha fazladır bu nedenle tüm implantlar çıkarıldıktan sonra sınıflandırma ameliyat sırasında doğrulanır veya değiştirilir. ${ }^{[7]}$ 
Sınıflama üç seviye kemik kaybını tanımlar. Tip 1 kemik kaybında, revizyon komponentinin stabilitesini bozmayacak derecede uygun normal eklem hattı seviyesi ile birlikte sağlıklı metafiziyel kemiğin olduğu minör kemik kaybı vardır (metafiziyel kemik sağlam). Tip 2 kemik kaybında komponentin tespiti için bir miktar kansellöz kemik desteğin kaybı vardır ve eklem hattı değişmiştir. Kemik kaybının bir veya iki kondili etkilemesine göre A ve B olarak da ikiye ayrılır. Tip 3 kemik kaybında ise tek başına revizyon komponentinin destekleyemeyeceği, kondil veya platonun büyük bir bölümünün olmadığı metafiziyel kemiğin ciddi kaybı bulunur. Bu sorunlar genellikle patellar tendon ayrışması ve kollateral bağ ya da ligament ayrılması ile birliktedir. ${ }^{[7]}$

\section{AMELIYAT ÖNCESI PLANLAMA}

Kemik kaybının tedavisini planlarken defektin etiyolojisini, sınıflamasını, kullanılacak protezleri, tüm tedavi seçeneklerini ve cerrahi teknikleri anlamak gereklidir. Uygun ameliyat öncesi planlamada kemik kaybını sınıflandırmak için iyi kalitede çekilmiş grafiler önemlidir. Tam ön-arka (AP) ve yan (lateral) grafiler, kemik defektinin yerini ve boyutunu tanımlamak için gereklidir. Tercihen ayakta basarak ve ağırık vererek çekilmelidir. Genellikle iki yönlü grafiye ilave dizin ek oblik grafisi, defektin daha ayrıntılı değerlendirilmesini sağlayabilir. Bilgisayarlı tomografi (BT), kemik kaybının ayrıntılı değerlendirilmesi için önemlidir. Ameliyat öncesi iyi bir planlama ile vidalar, metal kama ve destekler ile ameliyat sırasında karşılaşılacak duruma bağlı olarak kullanılacak contsrained (kısıtlayıcı) implantları da içeren çeşitli protez seçenekleri hazır bulundurulmalıdır. Tedavideki amaç; kemik stoğunu korumaya, implantı güçlü yapısal kemiğe sabitlemeye, anatomik bir eklem hattını yeniden oluşturmaya, fleksiyon-ekstansiyon stabilitesini yeniden sağlamaya odaklanmalıdır. Mümkün olduğunca yeterli diz stabilitesini sağlayan en az kısıtlayıcı implant kullanılmalıdır. Stemin tespiti; hastanın kemik kalitesi, hastanın yaşı ve implantı doğru bir konuma yerleştirme gibi birçok faktöre bağlıdır. Stemin uzunluğu, defektin boyutuna, tipine ve protez için ne kadar kısıtlama gerektiğine bağlıdır. Nadir durumlarda kollateral bağ bütünlüğünün ileri derecede bozulduğu diz instabilitesinin varlığında menteşe tipi veya rotasyona izin veren menteşe tipi kısıtlayıcı protez kullanılır. ${ }^{[1,2]}$

\section{PRIMER TOTAL DIZ PROTEZINDE KEMIK KAYBININ TEDAVISi}

Tedavi kemik kaybının tipine, büyüklüğüne ve yerine bağlıdır. Primer TDP'de, kemik kaybı genellikle varus veya valgus dizilim bozukluğuna (malalignment)

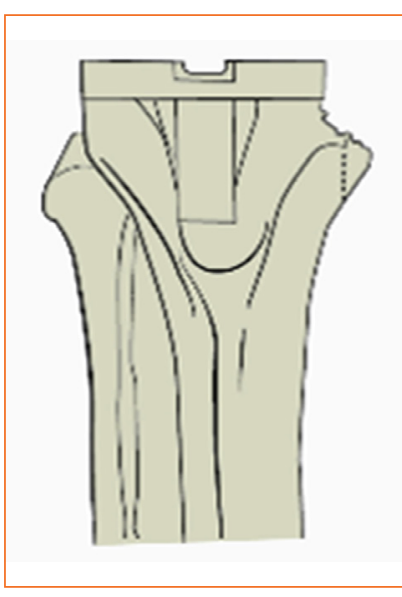

Şekil 2. Açısal deformitenin olmadığı küçük defektlerde tibial komponent daha sağlam kemiğe yerleştirilebilir.

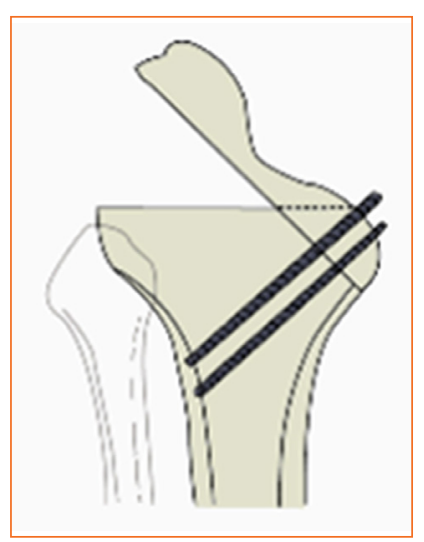

Şekil 3. Posteromedial segmenter defekt oblik kesi ile düzleştirilir ve distal femur rezeksiyonundan elde edilen kemik defekt bölgesine vida ile tutturulur. sekonder gelişir. Kaviter defekt eğer 5 mm'den küçükse, tibial rezeksiyonun daha alt seviyeden yapılması, komponentin defektten uzak bölgeye yerleştirilmesi önerilir veya vidalı/vidasız çimento uygulanır (Şekil 2). Defekt, 5 mm'den büyükse, otojen parçalanmış (morselize) kemik grefti veya yapısal oto ya da allogreft kullanılır (Şekil 3). Segmental defekt eğer $5 \mathrm{~mm}$ 'den küçükse, vida ile veya vidasız çimento, $5-10 \mathrm{~mm}$ arasında ise modüler kamalar, 10 mm'den geniş ise yapısal allogreft ve/veya modüler destek (augment) veya kişiye özel implantlar kullanılır. ${ }^{[1,2]}$

\section{Tibial rezeksiyonun daha alt seviyeden yapılması}

Tibial yüzeydeki kemik defekti genellikle çok sklerotik bir yatağa sahiptir; 6-12 mm derinlikteki defektlerde, tibianın $10 \mathrm{~mm}$ rezeksiyonu genellikle sklerotik yatağın çoğunu ortadan kaldıracaktır. Tibial rezeksiyon için sınır iliotibial bant (ITB)/infrapatellar ligamentin insersiyosudur. Bununla birlikte, aşırı tibial rezeksiyon, patellofemoral kinematiğin değişmesi, kalitesiz kansellöz kemik ve boyutlandırma problemlerine yol açabilir. Bu nedenle, mümkün olduğunca $10 \mathrm{~mm}$ 'den fazla tibiayı kesmemek gerekir (Şekil 4). ${ }^{[1]}$ 


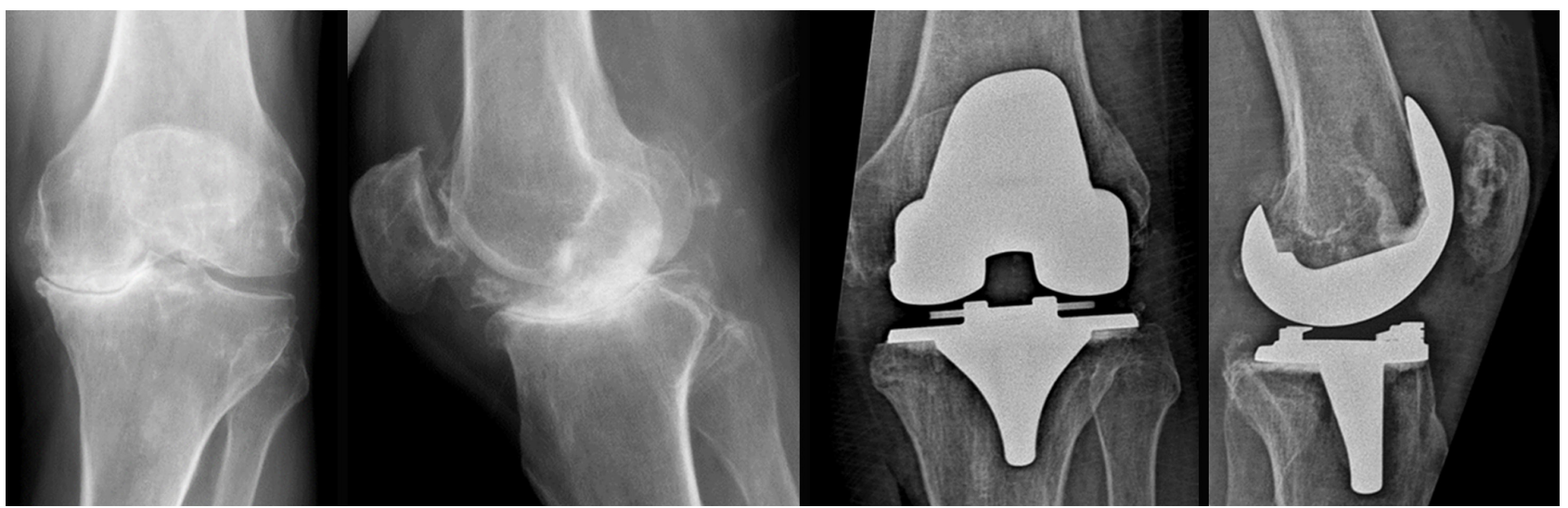

Şekil 4. Küçük defektlerde tibial rezeksiyonun alt seviyeden yapılması ve komponentin lateralizasyonu yeterlidir.

\section{Kemik çimento (Polymethylmethacrylate, PMMA) kullanımı}

Tibial rezeksiyondan sonra kemik defektleri 5 mm'den az ise tibial implantı desteklemek için kemik çimentosu (PMMA) ile doldurulabilir. Kaviter defektlerde ve yaşlı hastalarda tercih edilir. Kemik çimentosu, vidalı veya vidasız olarak çok küçük defektlerde dolgu maddesi olarak kullanılabilir. Kemik çimentosu ucuzdur, uygulaması kolaydır ve TDP yapılırken ameliyatın basamaklarını değiştirmez. Tibial komponent, platonun sağlam yönüne doğru kaydırılmalıdır. Doğru dizilimi sağlamak en önemli noktadır. Bununla birlikte, çimentonun özellikle makaslama kuvvetlerine karşı biyomekanik gücünün zayıf olması ve gelecekteki bir revizyon için kemik stoğunu koruyamama gibi bazı dezavantajları vardır. Daha geniş kapsamlı bir kaviter defekte, segmental defekte veya genç hastalarda defektin çimento ile güçlendirilmesi önerilmez. ${ }^{[1]}$

\section{Parçalanmış (morselize) kemik grefti}

Derinliği 12 ila 15 mm'den fazla olan kaviter defektlerde kemik grefti tercih edilen tekniktir. Otojen kemik grefti biyolojik açıdan mükemmel bir malzemedir. Primer cerrahide kemik defektlerini tedavi ederken hastaya daha sonra revizyon cerrahisi gerekeceği akılda tutulmalıdır. Bu yüzden kemik kaybını tedavi etmek için seçilecek tedavi modalitesi mümkün oldugunca biyolojik olmalıdır. Kemik greftler inkorpore ve remodele olur ve yük taşımada sement veya metal implantların yaptığından daha fizyolojik elastisite modülüsü ve trabeküler yapı sağlar. Primer protezde tantalum kullanımı bildirilmesine rağmen sıklıkla revizyon protezinde karşılaşılan kemik kayıpları için endikedir. ${ }^{[1]}$

\section{Yapısal kemik grefti}

Derinliğin $5 \mathrm{~mm}$ ile $15 \mathrm{~mm}$ arasında olduğu orta ile büyük arası segmental kemik defektleri için uygundur. Distal femoral rezeksiyondan elde edilen otojen kemik genellikle primer TDP'de yeterlidir. Sculco tekniğinde ilk adımda, standart proksimal tibial kesi yapılır ve testere daha sonra tibial defektin yanında oblik bir osteotomi oluşturmak için kullanılır. Kemik defektinin tabanı genellikle çok sklerotiktir ve rezeke edilmesi gerekir. Kemik defekti, greft birleşmesini kolaylaştırmak için sağlıklı kanayan kemiğe kadar debride edilir. Bu sklerotik kemiğin çıkarılması ve kansellöz kemiğin ortaya konması önemlidir, aksi takdirde greftin konsolidasyonu olmaz ve greftin kaynamaması meydana gelebilir. Bir sonraki adımda distal femoral keside elde edilen kemik, defekti dolduracak şekilde şekillendirilir. Genellikle medial femoral kondilin kansellöz yüzeyi, kemik defektinin kansellöz yüzeyiyle örtülür. Distal femoral greftin kondiler yüzeyinin nihai şekillendirilmesi, standart tibial kesme kılavuzları ile yapılabilir. Bu sabitleme daha sonra kanselöz vidalarla desteklenir (Şekil 5-8). Böylece tibianın üst yüzeyi tamamlanmış olur. Greftin implant ile kapatılması önemlidir. ${ }^{[3]}$

\section{Yapısal allogreft kullanımı}

TDP revizyonu sırasında büyük bir segmental defekti doldurmak için çoğunlukla büyük bir yapısal allogreft kullanılır. Ancak uzun vadeli bir başarı için greftin altta yatan konak kemik ile inkorpore olması gerekir. 10 mm'den daha büyük boyutta segmenter defektlerde endikedir. Allogreftlerin kemik kayıplarında kullanımının birçok avantajı vardır. Bunlar başlıca; kemik stoğunun yeniden sağlanması, biyo-uyumluluk, ligament bağlanma potansiyeli ve maliyet etkinliğidir. Dezavantajları arasında geç re-absorpsiyon, kaynamama, kırık ve hastalık 


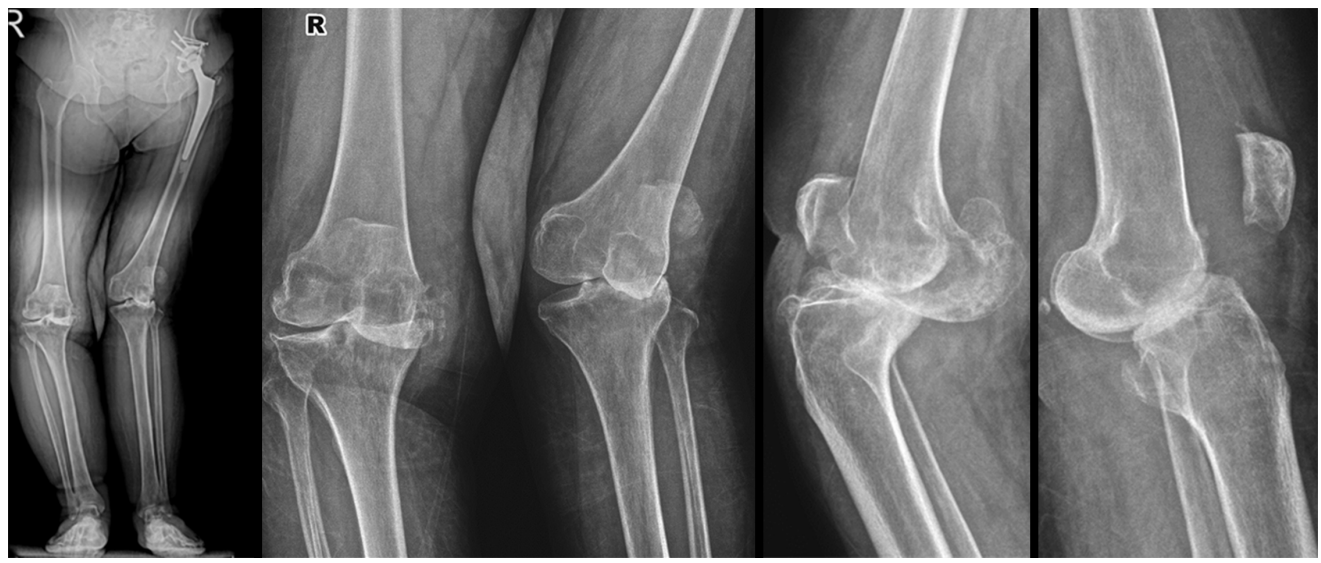

Şekil 5. Ameliyat öncesine ait; ortoröntgenografi, her iki diz ön-arka ve yan grafiler.

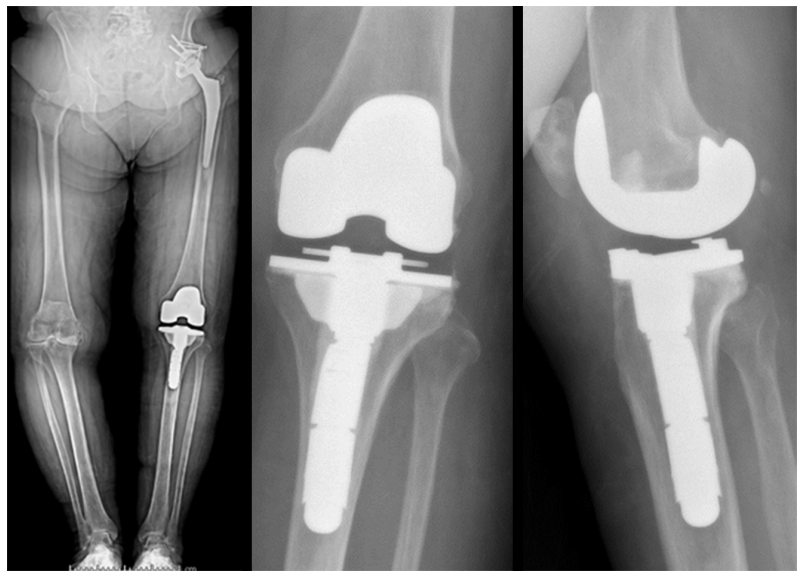

Şekil 6. Şekil 5'teki hastanın, sol taraf ameliyat sonrası grafileri; ortoröntgenografi, ön-arka ve yan grafileri.

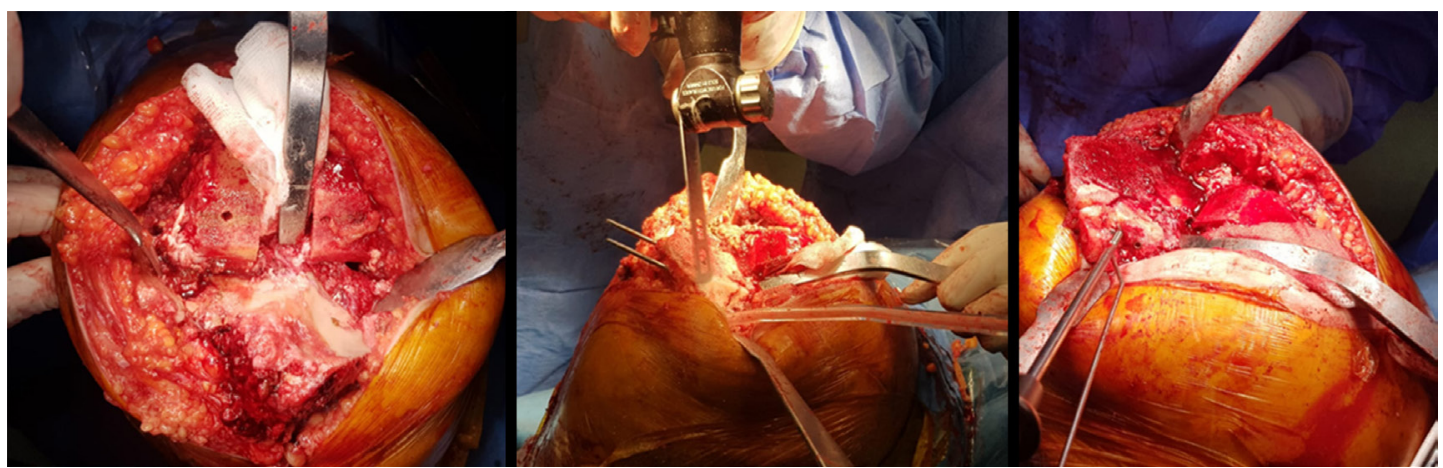

Şekil 7. Şekil 5'teki hastanın, sağ taraf ameliyat sırasında Sculco tekniği ile kemik kaybının rekonstrüksiyonu.

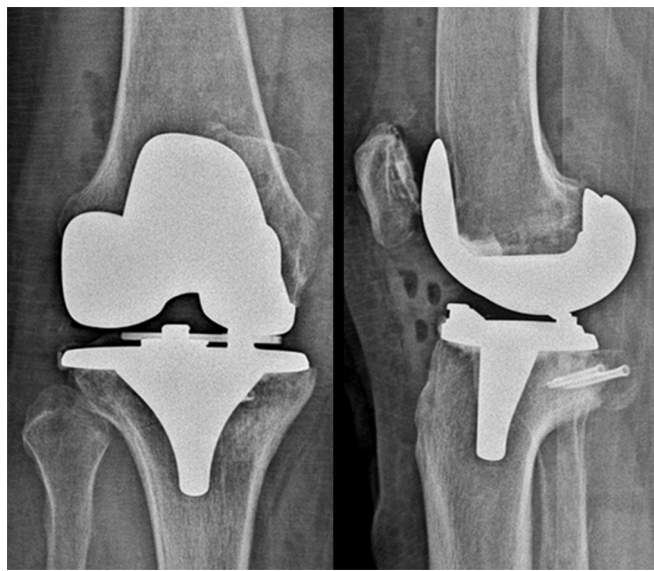

Şekil 8. Şekil 5'teki hastanın, sağ taraf ameliyat sonrası ön-arka ve yan grafileri. 
bulaşma riski sayılabilir. Mutlak kontrendikasyon kronik enfeksiyondur. Göreceli kontrendikasyonlar arasında immun baskılama, metabolik kemik bozuklukları, nöropatik artropati ve yetersiz ekstansör mekanizma yer alır. Konak kemiği, sağlıklı kanayan kemiğe kadar debride edilir. Proksimal tibia rezeksiyonu 1-2 mm kemiğin çıkarılmasıyla tazelenir ve böylece bu implantla konakçı kemik temasını en üst düzeye çıkarmak için düz bir yüzey bırakılır. Yapısal allogreft, defekti dolduracak şekilde şekillendirilir. Greftin mekanik uyumu zayıfsa, kansellöz kemik vidaları ile tamamlayıı tespit uygulanır.

\section{Kısmi veya tam genişlikte metal kama (wedge) destekler}

Modüler metal kama veya destekler, 5 ile $15 \mathrm{~mm}$ arasında değişen orta büyüklükteki segmental defektler için uygundur. Modüler metal destek blokları ve kamalar, konakçı kemik stoğunu geri getirmese de, uygun şekilde uygulandığında \%84 ile \%98 arası değişen iyi-mükemmel sonuçlarla dayanıklı implant stabilitesi sağlarken, yükleri sağlam ana kemiğe aktararak anında ağılık taşıma ve hareket aralığı sağlar. Sekonder implant yetersizliği ve zamanla düşük dirence bağlı olarak yaşlı hastalarda tercih edilmelidir. ${ }^{\left[{ }^{[8}\right.}$ Kemik grefti, metalik desteklerden ziyade tercih edilen bir yöntemdir, çünkü greftler kemik stoğunun yenilenmesine yardımcı olur. Son zamanlarda, trabeküler metal olarak adlandırılan gözenekli (poröz) metal, kama ve koni (cone) şeklinde çeşitli şekillerde uygulanan destekler, segmental defektlere veya kombine büyük kaviter ve segmental defektlere uygulanmaktadır. Çalışmalar, kemiğin ve hatta tendonun metaryale içe doğru (ingrowth) büyümesini sağladığını göstermiştir (Şekil 9-13). ${ }^{9,10]}$

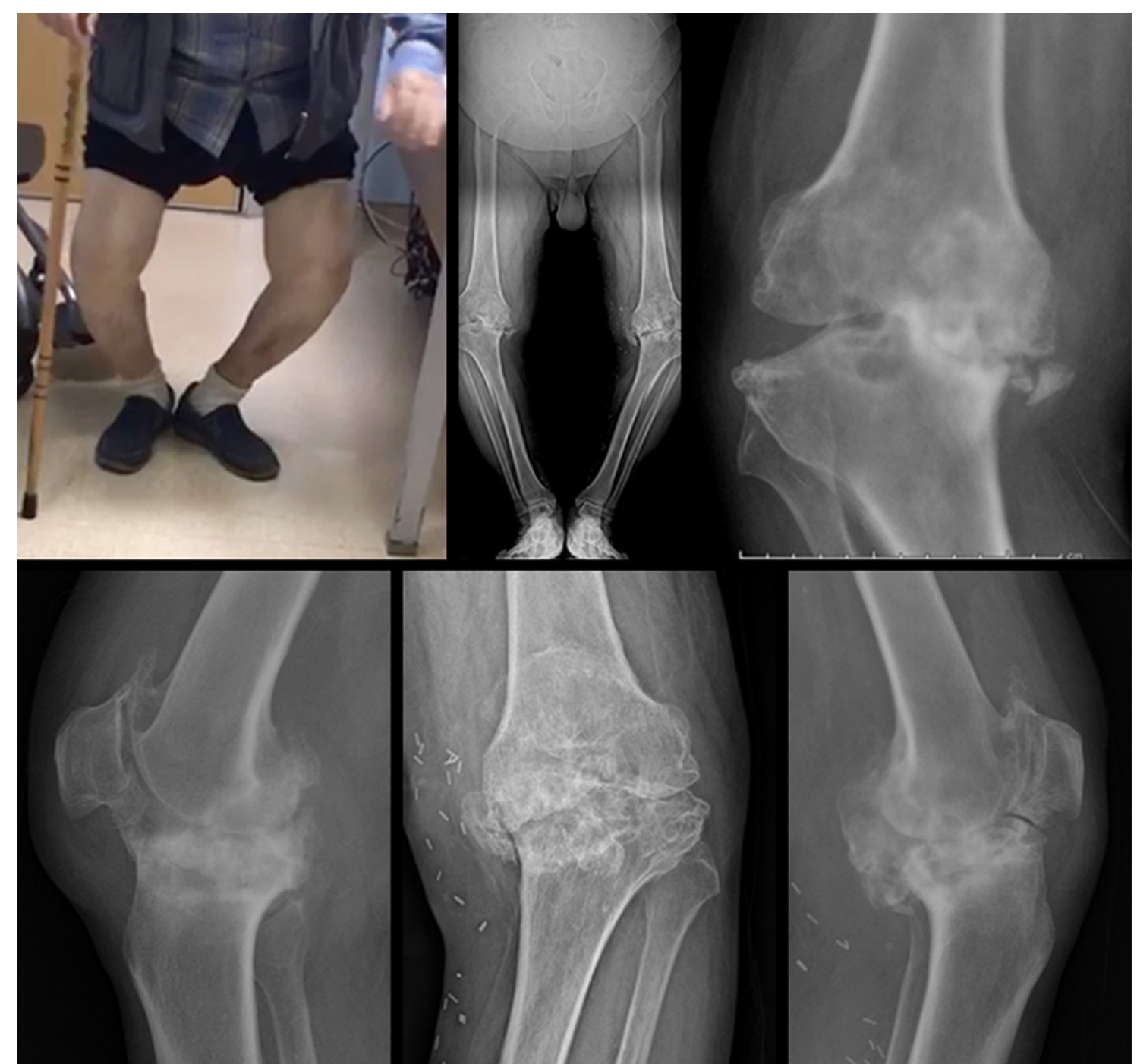

Şekil 9. Bilateral ciddi varus ve kemik kaybı olan diyabetik hastanın ameliyat öncesi klinik görünümü ve grafileri. 


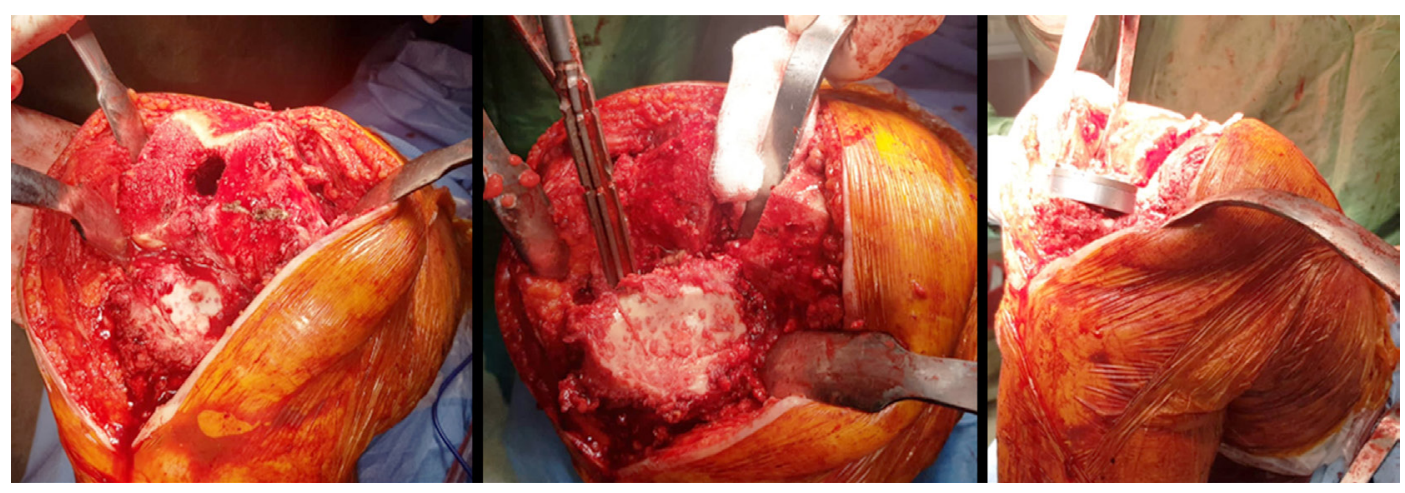

Şekil 10. Şekil 9'daki hastanın sağ dizinin ameliyat sırasındaki görüntüleri; medial tibiadaki kemik kaybı ve metal destek ile eklem hattının korunması.

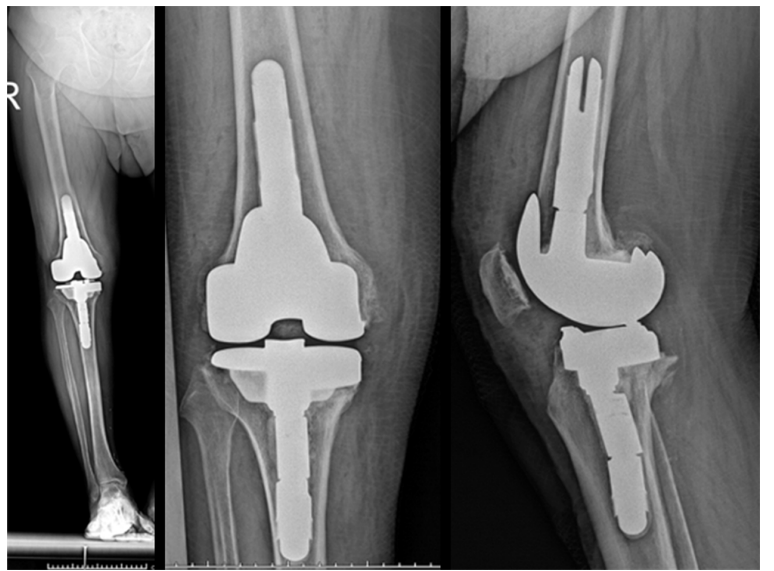

Şekil 11. Şekil 9'daki hastanın sağ dizinin ameliyat sonrası grafileri; sağ alt ekstremite uzunluk grafisi, ön-arka ve yan grafiler.

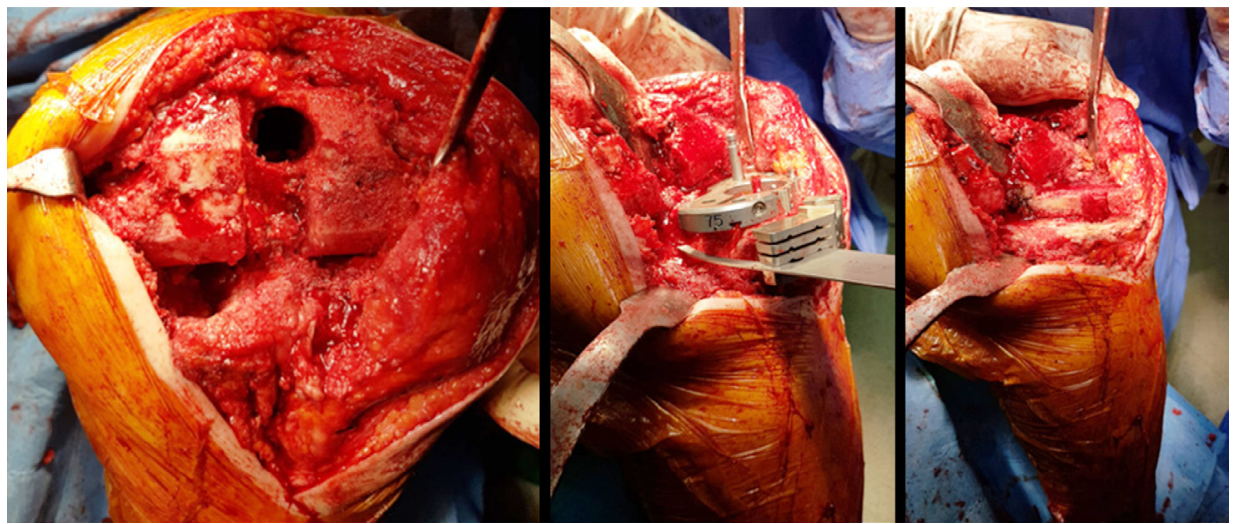

Şekil 12. Şekil 9'daki hastanın sol dizinin ameliyat sırasındaki görüntüleri; tibia medialindeki defekt için medial platonun blok kesisi.

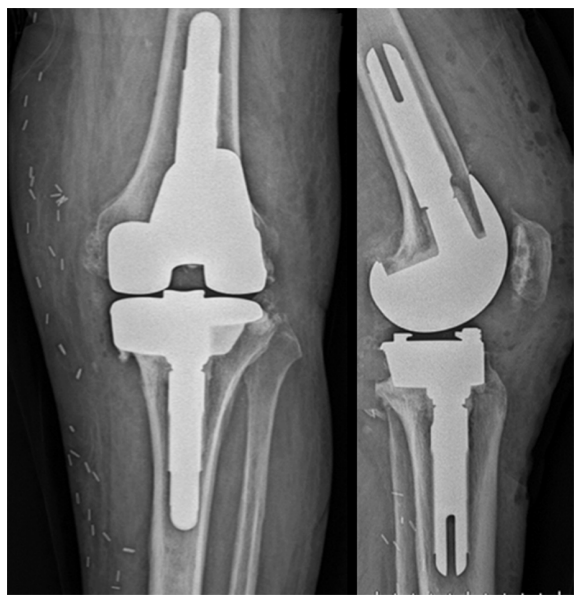

Şekil 13. Şekil 9'daki hastanın sol dizinin ameliyat sonrası ön-arka ve yan grafileri. 


\section{Ameliyat için önemli noktalar ${ }^{[8]}$ :}

- Ameliyat öncesi şablonlama ile tüm gerekli alet ve malzemeler hazırlanmalıdır.

- Genel olarak medial parapatellar artrotomi ile başlamak tercih edilir.

- Kemik defektlerini doğru bir şekilde ele almak için yeterli disseksiyon yapılmalı, sert ve kontraktürü olan dizlerde kuadriseps kesisi, kuadriseps turndown ve tibial tüberkül osteotomisi gibi cerrahi seçenekler uygulanmalıdır.

- Femoral komponent dizilimini sağlamaya yardım$\mathrm{cl}$ olmak için önce tibia kesilmelidir.

- Kemik defektleri en iyi şekilde femoral kemik kesisi standart bir şekilde yapıldıktan sonra değerlendirilir. Uygun protez boyutu tahmin edilerek uygulanmazsa, aşırı kemik kesisinde yüksek bir eklem çizgisi oluşturarak yerleştirilecek küçük femoral implant, fleksiyon stabilitesini tehlikeye atabilir. Kritik adım, eklem hattını genellikle medial epikondilin $30 \mathrm{~mm}$ distalinde veya lateral epikondilin $25 \mathrm{~mm}$ distalinde olacak şekilde belirlemektir.

- Eklem çizgisi ve femoral rotasyon için referans olacak epikondiler aks belirlenmelidir.

- Mümkünse defekt doldurmak için otojen greft kullanılır.

- Metal kama veya blok destekler özellikle yaşlı veya daha az aktif hastalarda en uygun seçenektir. Özellikle asimetrik kemik kaybı varsa, geçici bir metal destek (augment) tutturulan bir intramedüller kesme kılavuzu ile femur kesisi yapılır. Daha sonra metal destekle birlikte deneme komponentler ve intramedüller gövde, press-fit oturtulduktan sonra distal femur kesisi yapılır. İmplantın yanlış konumlandırılmasına neden olacaksa, offset gövde veya daha küçük gövde kullanılır. Bu yöntem, distal ve posterior femoral kondillerde gereksiz kemik kesilmesini önleyecektir.

- Orta ila büyük boyutta kortikal defektlerde modüler intramedüller stem kullanılmalıdır.

- Kollateral bağ yetersizse kısıtlayıcı bir protez tasarımı düşünülür.
Ameliyat sonrası süreç; küçük bir femoral defekt için kemik çimentosu veya kemik grefti ile rekonstrüksiyon ve orta büyüklükteki bir defekt için metal kama veya destek kullanılan hastalar için ameliyat sonrası tedavi primer TDP'den farklı değildir. Hasta aynı gün veya ertesi gün mobilize edilir. Yapısal bir kemik grefti veya allogreft kullanılan durumlarda altı hafta boyunca ağırlık taşımadan korunması önerilir. Hareket açıklığı ve güçlendirme egzersizleri teşvik edilir. Sonuç olarak kemik kayıplarını tedavi ederken amaç; eklem hattını eski haline getirmek, fleksiyon/ekstansiyon aralığını dengelemek ve uygun implant konumunu sağlamak için çimento, greft veya gerekirse metal kama veya destekleri uygulamaktır.[2]

\section{KAYNAKLAR}

1. Fosco M, Ayad R, Amendola L, Dallari D. Management of Bone Loss in Primary and Revision Knee Replacement Surgery. Rec Adv Arthroplasty 2012;387-410. Crossref

2. Tigani D, Trentani P, Trentani F, Marinelli A, Bianchi G, Fravisini $M$. The treatment of bone defects in primary arthroplasty of the knee. Chir Organi Mov 2004;89(1):2933. https://pubmed.ncbi.nlm.nih.gov/15382583/

3. Insall JN, Easley ME. Surgical Tecniques and Instrumentation in Total Knee Arthroplasty. In: Insall JN, editor. Surgery of the Knee, 3rd ed. New York: Churchill Livinsgtone; 2001. p.1553-620.

4. Insall JN. Revision of aseptic failed total knee arthroplasty. In: Insall JN, editor. Surgery of the Knee, 2nd ed. New York: Churchill livingstone; 1993. p.935-57.

5. Bargar WL, Gross TP. A classification of bone defects in revision total knee arthroplasty. Presented at the Knee Society Interim Meeting, Philadelphia, 1992.

6. Rand JA. Bone deficiency in total knee arthroplasty. Use of metal wedge augmentation. Clin Orthop Relat Res 1991;(271):63-71. Crossref

7. Engh GA, Ammeen DJ. Bone loss with revision total knee arthroplasty: defect classification and alternatives for reconstruction. Instr Course Lect 1999;48:167-75. https:// pubmed.ncbi.nlm.nih.gov/10098042/

8. Radnay CS, Scuderi GR. Management of bone loss: augments, cones, offset stems. Clin Orthop Relat Res 2006;446:83-92. Crossref

9. Sheth NP, Lonner JH. Clinical use of porous tantalum in complex primary total knee arthroplasty. Am J Orthop (Belle Mead NJ) 2009;38(10):526-30. https://pubmed.ncbi.nlm. nih.gov/20011743/

10. Gill UN, Ahmed N, Noor SS, Memon IA, Memon ZA. Management of the bone loss by metaphyseal sleeves in primary and revision knee arthroplasty: clinical experience and outcome after forty three cases. Int Orthop 2020;44(11):2315-20. Crossref 